\title{
TRANSMURAL MIGRATION OF A RETAINED SPONGE THROUGH BOWEL WALL CAUSING INTESTINAL OBSTRUCTION
}

\author{
Hanief Mohamed Dar*,1, Varun Dogra*, Sikender lqbal Lone* and Sheikh Imran Farooq* \\ *Department Of Surgery, Government Medical College, Srinagar, India
}

\begin{abstract}
Gossypiboma (GP) or retained surgical sponge is one of the rare surgical complications that can happen despite precautions. It is an avoidable surgical complication that can lead to increased patient Morbidity and profound Medicolegal implications. Abdominal textiloma may be asymptomatic or present serious gastrointestinal complications such as bowel obstruction, perforation or fistula formation because of misdiagnosis, it may mimic abscess formation in early stage or soft tissue masses in the chronic phase.
\end{abstract}

KEYWORDS Gossypibiloma, small bowel obstruction

\section{Introduction}

Gossypiboma (GP) / textiloma / gauzioma, a retained gauze is a rare surgical complication. Its incidence is much higher than reported in the literature due to medico-legal implications[1].

Mostly Gossipibomas have been described after abdominal surgeries. However, GP at other sites such as the neck, thorax and thigh have also been reported[2].

It may present in the early post-operative period or years later after surgery, or remain asymptomatic and diagnosed incidentally [3]. Within, we reported a case of intraperitoneal gossypiboma that has penetrated into ileum causing complete small bowel obstruction two months after lower segment caesarian section.

Copyright (C) 2016 by the Bulgarian Association of Young Surgeons DOI:10.5455/ijsm.20150719092903

First Received: June 17, 2015

Published Online: July 29, 2015

Manuscript Associate Editor: George Baytchev (BG)

Editor-in Chief: Ivan Inkov (BG)

Reviewers: Rajesh Godara (IN); Takashi Kobayashi (JP); Metehan Gumus (TR); Victoria Steelman (USA)

${ }^{1}$ Hanief Mohamed Dar, Department Of Surgery, Government Medical College,

Srinagar,India. Email:drhaniefms@gmail.com

\section{Case report}

33 years-old-female delivered by lower segment caesarian section (LSCS) two months back presented in surgical emergency with complaints of pain abdomen, vomiting multiple episodes, abdominal distension and absolute constipation for three days. Records of LSCS revealed a lot of intraoperative bleedings that was managed by difficulty.

On examination, she was ill looking, conscious, oriented with a heart rate of $100 / \mathrm{min}$, respiratory rate of 22 breaths/min, the temperature of $1000 \mathrm{f}$ and BP of $110 / 70 \mathrm{mmHg}$. An infraumbilical midline scar of LSCS was present, done two months back. Abdominal fullness and moderate diffuse tenderness found on examination. Laboratory workup revealed $\mathrm{Hb}$ of $9.0 \mathrm{gm} / \mathrm{dl}$ and TLC of $14 \times 10(9) / \mathrm{L}$.

Air fluid levels noticed on erect abdominal X-ray. Ultrasonography abdomen showed distended gut loops and a heterogeneous mass in the right lower abdomen. Computerised tomography abdomen showed 9x10 cms mass with hyperdense foci within it in the right upper paramedian region and distended small gut loops. [Figure 1]

During surgery, a $10 \times 10 \mathrm{~cm}$ mass was seen in distal ileum $20 \mathrm{~cm}$ proximal to the ileocecal region with distended proximal stomach and severe dense adhesion with jejunum sigmoid colon and the parietal wall. With gentle dissection, adhesions were separated out, and the mass lesion was excised out with six cms margins on either side. Ileo-ileal anastomosis established bowel continuity. 

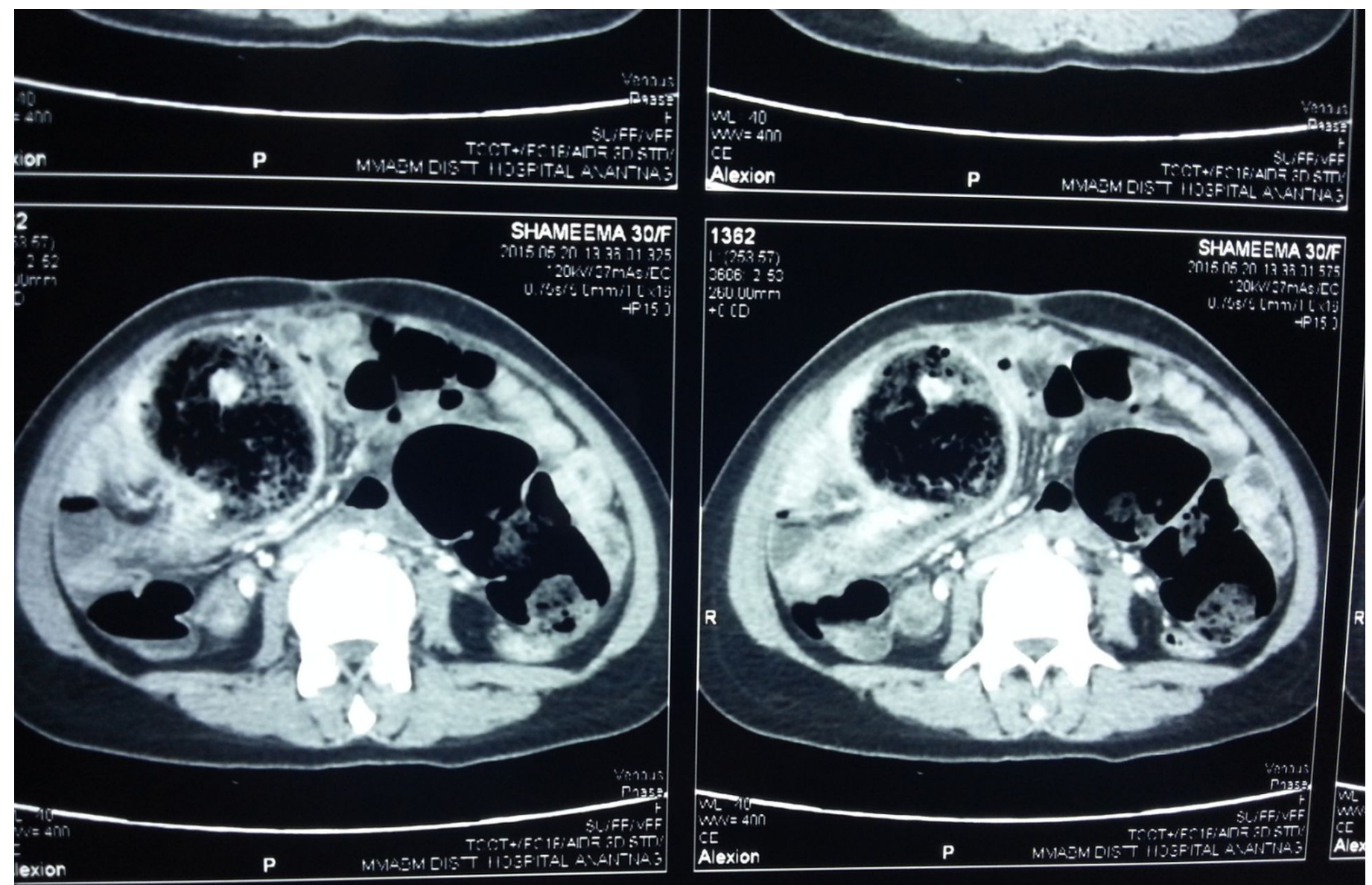

Figure 1: Computerised tomography is showing sponge in bowel lumen with distended gut loops.

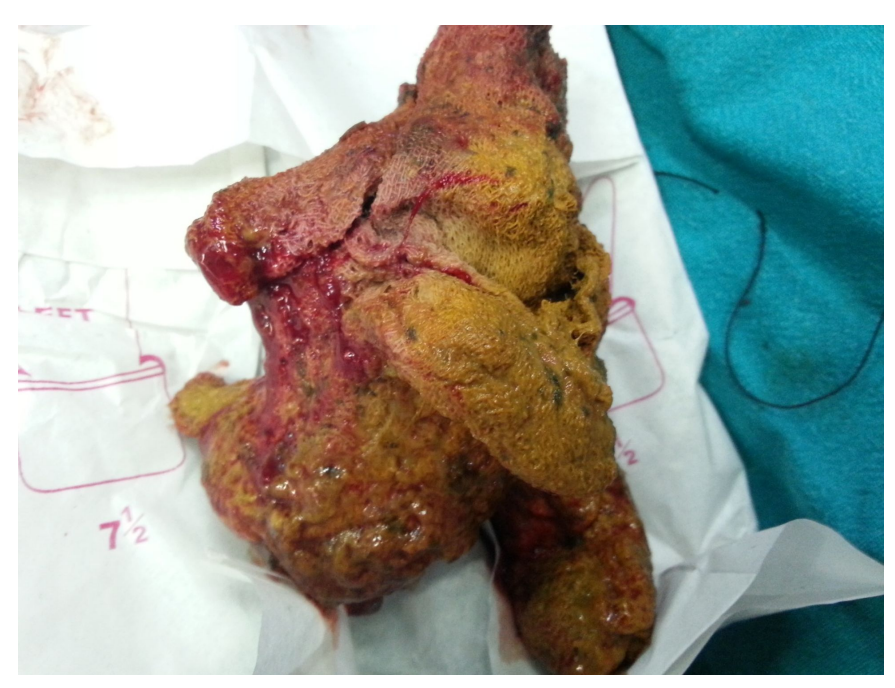

Figure 2: Evacuated surgical sponge.
On incising the mass, a big retained surgical sponge was found.[Figure 2] Postoperative period was uneventful. Oral feeds started on fifth postoperative day and patient was discharged on the 7th day. [Figure 3]

\section{Discussion}

Gossypiboma defined as a mass of cotton matrix retained within the human body following surgery (Gossypium: Latin word meaning cotton and Boma: Swahili word meaning a place of concealment[4]. It can produce two types of foreign body reactions.

An aseptic fibrinous response that can form a granuloma or pseudotumor that often follows a silent course. The others follow an exudative response that leads to abscess formation and produce immediate symptoms. It may go unnoticed up to years or may result in intestinal obstruction, fistula formation, peritonitis, abscess formation, spontaneous expulsion and erosion into a neighboring blood vessel. It may also observe in cases of transmural migration into small bowel, stomach, large bowel or urinary bladder and 10\% mortality [5].

Foreign bodies may ultimately migrate into the ileum without any apparent opening in the intestinal wall. 


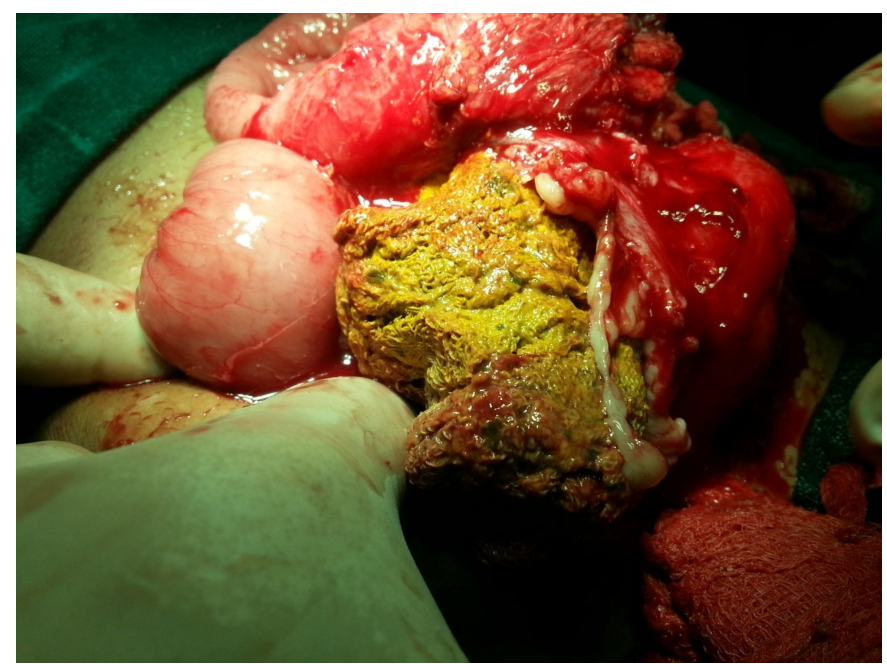

Figure 3: Surgical sponge in the bowel lumen.

They usually cannot pass the ileocecal valve and cause complete intestinal obstruction at this level. However, if they can go through this valve, they are quickly discharged through the anus [6].

Imaging modalities used to gossypibomas include radiographs, ultrasound abdomen, computerized tomography and MRI abdomen. Sonographic findings in cases of gossypiboma can be divided into three types as follows:

- hyperechogenicity image with posterior acoustic shadowing;

- well-defined mass with cystic contents and echogenic, undulated internal structures;

- non-specific finding of complex and/or hypoechoic mass. Invariably, internal vascular flow is absent at Doppler study.

At CT, gossypibomas are identified as a mass with welldefined contours, with soft tissues density and high or even mixed masses. Sometimes containing air bubbles and highdensity capsule that may presents enhancement in the postcontrast phase[7].

Gossypibomas appearance at MRI is varied, being most commonly identified as a heterogeneous mass, sometimes showing a solid-cystic component, with well-defined contours, surrounded by a well-delimited capsule. Hyposignal and hypersignal predominate respectively on T1-weighted and T2-weighted images, including internal serpiginous and irregular images with the intermediate signal on both T1- and T2- weighted imaging.[8].

\section{Conclusion}

Although surgery is the recommended mode of treatment, prevention is best. During surgery, there should be a clear record of all foreign materials used, without exception. Textile materials used should impregnate with radiopaque markers. At the end of the procedure, the surgical site should be thoroughly checked for any retained foreign bodies and incision should be closed after the consent of theatre assistant[9].

\section{Authors' Statements}

Competing Interests

The authors declare no conflict of interest.

\section{References}

1. Atay M., Ahmad IC., Bilgin M., Kocakoc E.. Gossypiboma/textiloma mimicking as tumour recurrence. J Pak Med Assoc. Vol. 64, No. 6, June 2014.

2. Singh C, Gupta M. Gossypiboma versus GossipBoma. Case Reports in Radiology. 2011;2011:705062. doi:10.1155/2011/705062.

3. Khan YA, Asif M, Al-Fadhli W. Intraluminal Gossypiboma. APSP Journal of Case Reports. 2014;5(2):17.

4. Khan HC., Malik AA., Ali S. et al. Gossypiboma as a Cause of Intestinal Obstruction. Journal of the College of Physicians and Surgeons Pakistan 2014, Vol. 24 (Special Supplement 3): S188-S189.

5. Hariharan D, Lobo DN. Retained surgical sponges, needles and instruments. Ann R Coll Surg Engl 2013; 95:87-92.

6. Manzella A., Filho PB., Albuquerque E., et al.Imaging of Gossypibomas: Pictorial Review. AJR:193, December 2009

7. Neto FAC., Agnollitto PM., Mauad FM., et al. Imaging findings of abdominal gossypibomas. Radiol Bras. 2012 Jan/Feb;45(1):53-58.

8. Martins MCB, Amaral RPG, Andrade CS, et al. Características de imagem na ressonância magnetic de gossipiboma intracraniano: relato de caso e revisão da literatura. Radiol Bras. 2009;42:407-9.

9. Sharma D., Pratap A., Tandon A., et al.Unconsidered cause of bowel obstruction - gossypiboma. E34 J can chir, Vol. 51, No 2, april 2008. 